손목굴증후군의 진단과 치료에서 신경초음파

신유용 김상범

강동경희대학교병원 신경과

\title{
Neurosonography in Diagnosis and Treatment in Carpal Tunnel Syndrome
}

\author{
Yu Yong Shin, Sang Beom Kim \\ Department of Neurology, Kyung Hee University Hospital at Gangdong, Seoul, Korea
}

\begin{abstract}
Neurosonography is now considered an effective method to evaluate peripheral nerves. Low cost, high resolution, the ability to image an entire limb in a short time, and dynamic assessment are several of the positive attributes of ultrasound. Ultrasonographic (US) studies have proven to be very useful in diagnosis and localization of focal neuropathies in the upper extremities. They are most useful to answer specific questions unresolved by the neurological examination and electrodiagnostic (EDX) studies. US studies can be regarded as complementary to EDX studies because they provide most of the information that EDX studies has not shown. Often, it is very useful to have US equipment always on hand to allow you to use it during EDX studies. This article will review the normal appearance of peripheral nerves as shown with US. In addition, the US findings, pathophysiology and management of the entrapment neuropathy focusing on carpal tunnel syndrome will be reviewed.
\end{abstract}

\section{J Neurosonol Neuroimag 201\&;10(1):19-24}

Key Words: Ultrasonography; Median nerve; Carpal tunnel syndrome
Received: June 4, 2018

Revised: June 12, 2018

Accepted: June 12, 2018

Address for correspondence: Sang Beom Kim

Department of Neurology, Kyung Hee University Hospital at Gangdong, 892 Dongnamro, Gangdong-gu, Seoul 05278, Korea

Tel: $+82-2-440-6168$

Fax: $+82-2-440-7242$

E-mail: sbkim@khu.ac.kr

\section{서 론}

초음파는 말초신경을 평가하는 훌륭한 도구로 증명되고 있 으며, 높은 정확도로 많은 신경질환들을 진단할 수 있다. 초음 파를 사용하면, 자기공명영상검사에서 소요되는 시간보다 짧 은 시간에 고해상도로 사지의 신경을 볼 수 있다. 초음파로 실 시간 검사를 하면, 탐색자(probe)로 비정상인 신경이나 신경 종(neuroma)에 압력을 가하여 증상을 쉽게 유발할 수 있는데 (초음파 Tinel 징후), 이 때 환자로부터 직접 피드백을 받아, 진단의 정확성을 올릴 수 있게 된다. 관절을 움직이거나 근육 을 수축시켜서 역동적으로 신경을 평가할 때 초음파를 사용하 면 쉽게 할 수 있다. ${ }^{1}$ 본 종설에서는 말초신경의 정상초음파 영 상과 신경포착(nerve entrapment)과 같은 흔한 신경질환 중 손목굴증후군(carpal tunnel syndrome)에 대하여 살펴보고 자 한다.

\section{본 론}

1. 정상 말초신경의 초음파

초음파에서 말초신경의 특징적인 외관은 신경을 횡단면 (transverse plane)으로 볼 때 잘 나타나며, 개별 신경다발 (nerve fascicle)은 저에코(hypoechoic)로 보이며, 고에코 (hyperechoic) 결합조직에 둘러싸여 있다. 이 모양은 벌집 (honeycomb)처럼 보인다. 더 근위부의 신경줄기는 고에코 지 방으로 둘러싸여 있으며, 개별 신경줄기(nerve trunk)는 원위 부에서 단 하나의 신경다발로 이어진다. 종단면(longitudinal plane) 신경 영상에서, 신경다발의 외관이 잘 보이는데, 개 별 저에코의 신경다발이 주위의 고에코의 결합조직에 둘러싸 인 모양이다. 이 외관은 정상 힘줄과 잘 대비되는데, 정상 힘 줄은 초음파에서 원섬유모양(fibrillar pattern)의 고에코로 보 인다. $^{2}$ 횡단면으로 신경을 볼 때 중요한 것은 초음파 탐색자를 
보고자 하는 신경에 수직으로 각도를 유지하는 것이다. 그럼으 로써, 결합조직이 고에코로 보이며, 저에코의 신경다발이 더 눈에 잘 띄게 된다. 음파각도(insonation angle)를 기울이면 힘줄(tendon)과 같은 고에코의 결합조직층이 비등방성(anisotrophy)으로 인하여 저에코로 보이게 되며, 말초신경과 구별 이 쉽지 않을 수 있다.

\section{2. 말초신경 포착}

신경은 외부로부터 기계적인 접촉으로 인하여 압박되거나, 일반적으로는 무해한, 인대나 비후근육과 같은, 신체 조직의 일부에 의하여 포착되면 손상이 생길 수 있다. ${ }^{3}$ 보통 압박 부 위에서 부종이 생기면 신경단면적이 정상상한보다 증가한다. 포착이 중증도가 되면, 포착 부위에서 신경조임이 증가하게 되 어 신경단면적이 근위부 및 원위부보다 감소하게 된다. 척골 신경의 경우, $2 \mathrm{~mm}^{2}$ 이상 차이가 나기도 하는데, 신경포착 부 위 근위부가 원위부보다 단면적이 증가하여 모래시계 모양으 로 된다. 초음파에서 보이는 말초신경 포착의 전형적인 특징은 포착 부위와 그 근위부의 말초신경의 저에코 부종(hypoechoic swelling)이다. 빼섬유굴(osteofibrous tunnel)이나 기타 포 착 부위의 크기에 따라, 포착 부위를 통과하면서 신경은 각각 그 관이나 공간을 지나며 정상 크기로 이행(transition)한다. ${ }^{4}$ 포착의 초기 초음파 소견은 신경줄기의 결합조직층의 에코발 생(echogenicity) 감소이며, 신경이 전반적으로 저에코로 보 인다. 후기에 신경은 팽대되고, 비정상적인 신경분절에 탐색 자로 압력을 가하면, 침범된 신경의 분포를 따라 증상이 유발 된다(초음파 Tinel 징후), 침범된 신경이 지배(innervation)하 는 원위부 근육에서도 탈신경변화(denervation change)를 평 가해야 하는데, 근육의 에코발생이 비정상적으로 증가하며, 후 기에는 근육크기가 감소하는 위축(muscle atrophy)이 발생한 다. 포착신경병을 검사할 때 중요한 점은 신경 포착을 일으키 는 부위를 정확하게 평가하는 것으로, 포착 부위는 보통 침범 된 신경이 빼섬유굴을 통과하는 곳이다.
신경검사 방법은 다음과 같다. $12 \mathrm{MHz}$ 이상의 직선탐색자 로 상하지 신경의 전장을 검사하는데, 병터가 의심되는 신경의 횡단면을 검사할 때에는 최대면적과 최소면적을 측정한다. 면 적 측정 시에는 추적법을 이용하여 고에코의 가장자리를 제외 한 안쪽면을 재는데, 횡단면영상에서 신경이 항상 원모양은 아 닐 수 있기 때문에, 자동타원측정기능보다는 추적법이 더 정확 하게 면적을 잴 수 있다. ${ }^{5}$ 이상 부위에서는 종단면영상도 확인 한다. 신경횡단면적과 그 위치, 참고치와 영상을 보고서에 담 는다. 각 초음파검사실마다 고유한 정상 참고치를 보유하는 것 이 추천된다. ${ }^{6}$ 또한 손목에서는 정중신경의 이동성을 평가하기 위하여 손가락을 굴곡-신전시킨다.

신경부종의 기전은 다음과 같이 추정된다. 축삭형질 흐름 (axoplasmic flow)의 차단, 신경내막(endoneurium)의 부종, 신경내막과 다발막(perineurium)의 염증, 재수초화, 원위부 축삭변성, 축삭발아(axonal sprouting) 그리고 신경다발막과 외막(epineurium)의 섬유화 등으로 포착된 신경이 비대해진 다고 추정한다. ${ }^{7}$

흔한 포착신경병은 손목굴(carpal tunnel)의 정중신경과 팔 꿉굴(cubital tunnel)의 척골신경을 포함한다. 포착신경병 환 자는 종종 포착신경이 지배하는 근육의 위약을 호소하는데, 포 착 부위 근위부의 근육은 침범되지 않는다. 따라서, 신경지배 의 유형을 알아야 포착 부위를 국소화하는데 도움을 받을 수 있다. 또한, 환자는 포착신경의 감각분포영역에서 통증이나 저 림을 자주 호소한다. 손목굴에 대한 Phalen 검사와 같이 신경 에 대한 압박을 증가시키는 유발수기(provocative maneuver)는 통증이나 저림을 악화시키는데, 초음파 탐색자로 신경 에 직접 압력을 가하여 유사한 증상을 일으킬 수 있다. 비슷하 게, 포착 부위에서의 Tinel 검사도 종종 통증이나 저림을 유발 한다. 초음파 외에, 전기진단검사도 포착신경병을 확인하는 유 용한 진단기법이다. 포착신경병의 전기진단검사 소견은 포착 부위를 지나는 운동과 감각신경의 잠복기 지연(prolongation of latency)과 속도감소이며, 초음파검사 소견과 부합된다. 초 음파와 전기진단검사는 상호 보완적이며, 팔꿉굴 척골신경병
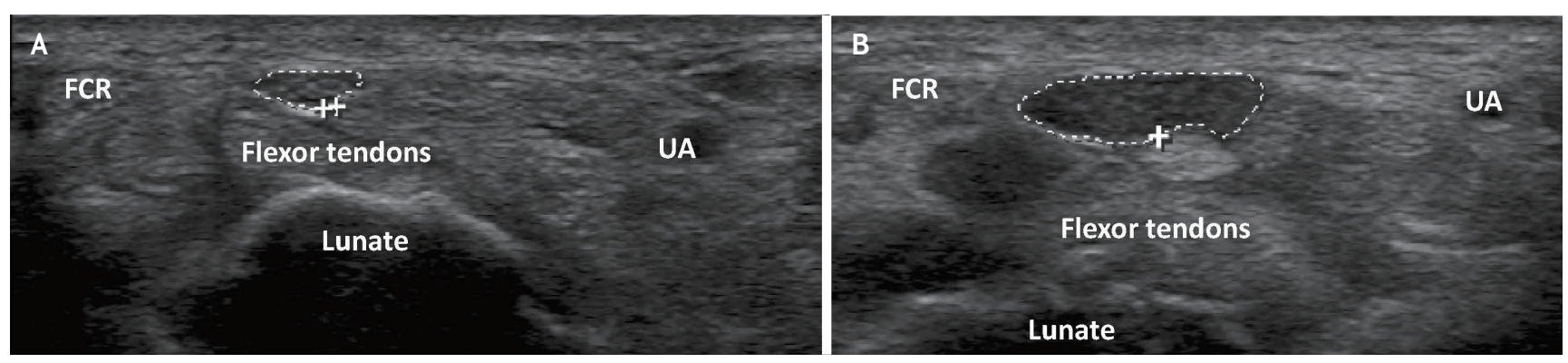

FIG. 1. Imaging of median nerve. (A) Normal right median nerve at the distal wrist crease with a cross-sectional area measuring $6.4 \mathrm{~mm}^{2}$ obtained with a $15 \mathrm{MHz}$ linear array transducer Philips HDı1 XE (Koninklijke Philips N.V., Ann Arbor, MI, USA). (B) For comparison, an abnormal right median nerve at the distal wrist crease shows hypoechogenicity and an enlarged cross-sectional area measuring $25.6 \mathrm{~mm}^{2}$. FCR; flexor carpi radialis, UA; ulnar artery. 
의 평가에서, 초음파를 전기진단검사에 추가하면, 민감도를 $78 \%$ 에서 $98 \%$ 로 올릴 수 있으며, 전기진단검사 단독으로는 확 인할 수 없는 병변을 국소화할 수 있다. 8,9

\section{3. 손목굴증후군}

정중신경은 9 개의 손가락굽힘근힘줄과 함께 좁은 뼈섬유로 이루어진 손목굴 안으로 주행하며, 정중신경의 포착은 내용물 에 비하여 제한된 공간 때문에 발생한다. 손목굴은 손바닥 쪽 의 가로손목인대(transverse carpal ligament)나 굽힘근지지 띠(flexor retinaculum)와 손등 쪽의 손목뼈(carpal bone)로 둘러싸인 뼈섬유굴이다. 굽힘근지지띠는 근위부에서는 콩알뼈 (pisiform bone)와 손배뼈결절(tubercle of scaphoid bone) 과 연결되며, 원위부에서는 갈고리빼(hook of hamate bone) 와 작은마름뼈(trapezoid bone)에 닿는다. ${ }^{10}$ 정중신경, 얕은 손가락굽힘근(flexor digitorum superficialis), 깊은손가락 굽힘근(flexor digitorum profundus)은 손목굴 안에 위치하 며, 인접한 노쪽손목굽힘근(flexor carpi radialis)은 손목굴 밖에 있다(Fig. 1A). 주위의 Guyon관에는 척골신경과 척골
동맥이 놓여있다. 정중신경포착이 특발성이거나 과다한 손사 용에서 비롯되기는 하지만, 결절종(ganglion cyst)이나 윤활 막염(synovitis) 등과 같은 손목굴 내의 공간점유병터(space occupying lesion)들이 이차(secondary) 손목굴증후군을 일 으키기도 한다.

손목굴증후군은 3-10\%의 유병률을 보이는 가장 흔하고 중 요한 국소신경병이다. ${ }^{11,12}$ 초음파로 연구된 첫 포착신경병이 며, 초음파의 진단가치가 입증된 첫 질환이다. ${ }^{13}$ 손목굴증후군 의 진단은 임상적으로 하는데, 초음파와 전기진단검사로 근거 가 된다. ${ }^{14}$ 환자들은 보통 첫 번째부터 세 번째 손가락과 네 번 째 손가락 노쪽 절반의 손바닥 쪽(정중신경의 감각신경지배영 역)의 무감각과 감각이상을 호소한다. 손 쥐는 힘이 감소하며, 후기에는 엄지두덩근육(thenar muscle)의 위축이 발생한다. 통증은 위팔로도 방사(radiation)되는데, 어깨까지 뻗치기도 한다. 통증과 감각이상은 종종 밤에 악화되고, 반복적으로 손 목을 굽힐 때 증상이 심해지는 양상을 보인다. 신체검사에서, 손목의 Phalen 검사와 Tinel 검사는 통증이나 감각이상을 악 화시키는 유발수기로 쓰인다. 첫 번째, 두 번째 벌레근(lumbrical muscle)과 엄지맞섬근(opponens pollicis muscle), 짧
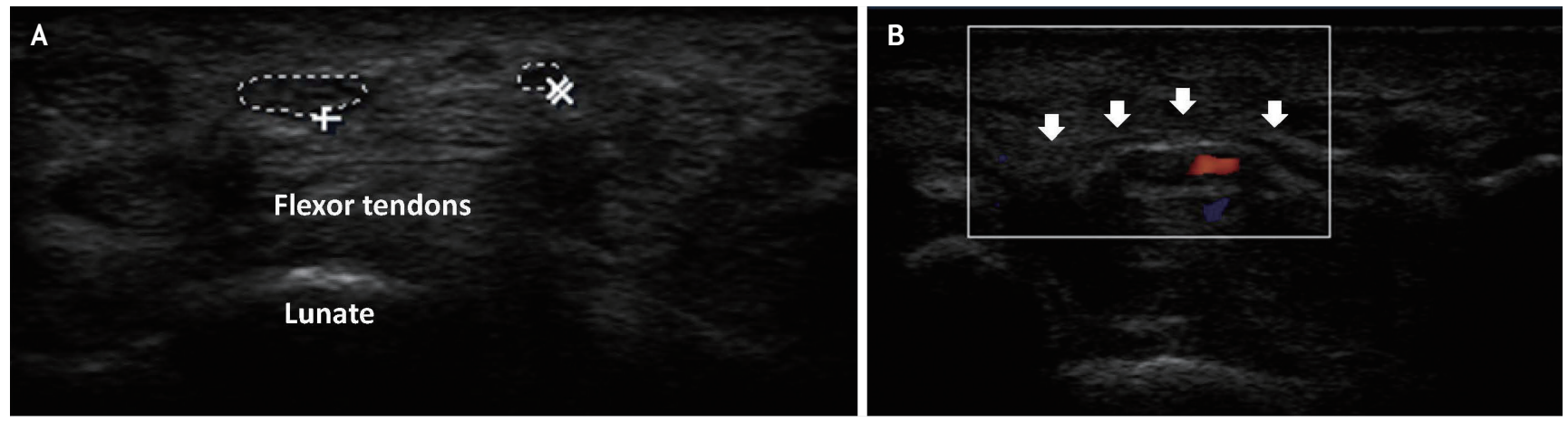

FIG. 2. (A) Bifid median nerve at distal wrist crease showed division of two branches before transverse carpal ligament with a $15 \mathrm{MHz}$ linear array transducer Philips HDı1 XE (Koninklijke Philips N.V., Ann Arbor, MI, USA). (B) Persistent median artery was residual at carpal tunnel by red color of color Doppler scan. Arrows indicate transverse carpal ligament.
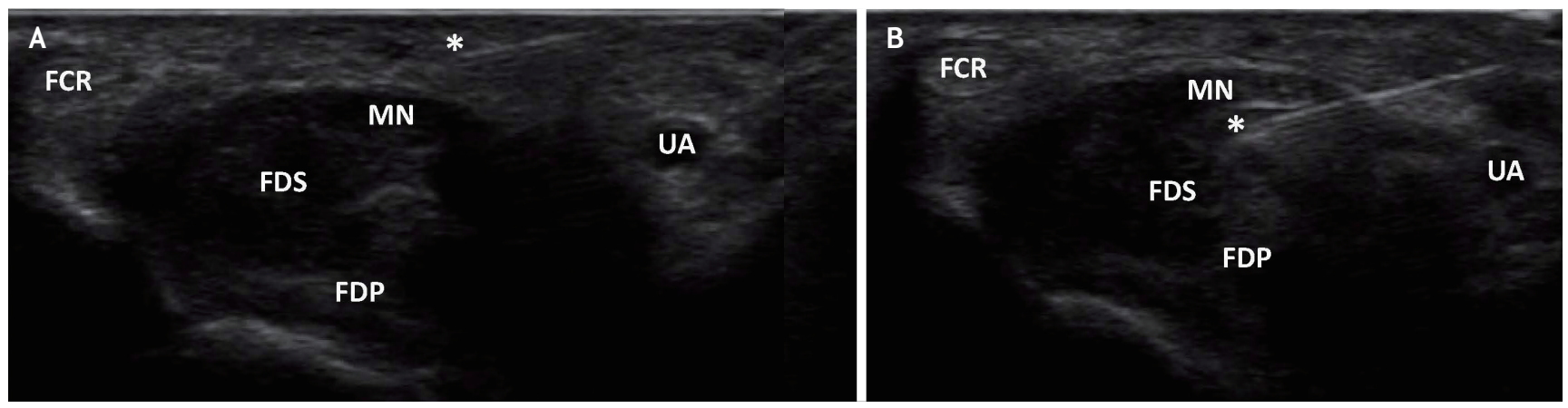

FIG. 3. (A) Sono-guided injection of local anesthetics and steroid mixture was performed to upper perineural portion of median nerve at just proximal to transverse carpal ligament. (B) Sono-guided injection of local anesthetics and steroid mixture was performed to lower perineural portion of median nerve at just proximal to transverse carpal ligament. FCR; flexor carpi radialis, *; needle tips, MN; median nerve, UA; ulnar artery, FDS; flexor digitorum superficialis, FDP; flexor digitorum profundus. 
은엄지벌림근(abductor pollicis brevis muscle), 짧은엄지굽 힘근(flexor pollicis brevis muscle)을 포함한 정중신경이 지 배하는 근육들이 위약을 보인다.

손목굴증후군은 초음파에서 보이는 비정상인 저에코로 팽 대된(abnormal hypoechoic enlarged) 정중신경이 특징이다 (Fig. 1B). ${ }^{15}$ 신경부종은 보통 굽힘근지지띠의 근위부 가장자 리에 생기지만 더 근위부로 확대되거나 드물게는 원위부인 손 목굴로 진행되기도 한다. 손목굴증후군의 초기 소견은 신경다 발을 싸고 있는 결합조직층의 에코발생이 감소하는 것인데, 그 정도가 경미할 수 있다. 정중신경의 팽대를 측정하면, 초음파 로 조금 더 객관적인 평가가 가능해진다.

손목굴증후군이 생겼을 때, 비정상인 정중신경팽대를 진단 할 수 있는 역치(threshold)는 민감도(sensitivity)와 특이도 (specificity)가 어떠한 기준을 선택하느냐에 따라 다르다. 일 반적으로, 정상 정중신경단면적은 손바닥쪽 손목주름(distal wrist crease)에서 $8 \mathrm{~mm}^{2}$ 미만이며, $8-12 \mathrm{~mm}^{2}$ 는 경계선, $12 \mathrm{~mm}^{2}$ 초과는 이상으로 간주한다. ${ }^{15}$ 정중신경팽대의 정도 는 신경전도검사로 진단된 손목굴증후군의 중증도(severity) 와 관련되는데, $12.8 \mathrm{~mm}^{2}$ 까지는 중등도(moderate grade)로, $14 \mathrm{~mm}^{2}$ 부터는 중증(severe grade)으로 본다. ${ }^{16}$ 환자마다 정 중신경의 크기가 다를 수 있기 때문에, 손목굴증후군을 평가할 때, 정중신경면적의 변화양상이 조금 더 정확한 기준이 될 수 있다. 경도-중등도에서는 포착 부위와 그 근위부가 원위부보 다 더 붓고, 중증도에서는 근위부>포착 부위>원위부, 극심한 중증도에서는 근위부>원위부>포착 부위 순으로 부종이 생긴 다. ${ }^{17}$ 손목과 아래팔의 단면적 비(wrist-forearm ratio)도 1.9 이상으로 증가한다. ${ }^{17,18}$ 신경의 에코발생이 감소하기 때문에 신경의 다발양상(fascicular pattern)이 소실되며, 굽힘근지지 띠의 구부러짐(bowing)도 $4 \mathrm{~mm}$ 이상이 된다. ${ }^{19-21}$ 신경편평 비(flattening ratio)도 3 이상이면 신경외양의 급격한 변화를 반영하는데 유용하다. 손목을 종단면영상으로 검사하면 V자패 임징후(notch sign)도 보인다. ${ }^{19}$ 관찰하는 것이 기술적으로 쉽 지는 않지만 신경의 혈관분포도(vascularity)도 증가한다. ${ }^{22}$ 신경의 횡적 이동성이나 종적 미끄러짐도 줄어든다. ${ }^{23}$

Klauser 등 24 은 전기진단검사를 참고기준으로 삼아 손목굴 증후근을 진단할 때, 근위부 네모엎침근(pronator quadratus muscle)에서 측정한 정중신경단면적과 손목주름에서 잰 최고 팽대 부위(maximal enlargement) 단면적의 차이가 $2 \mathrm{~mm}^{2}$ 를 초과할 경우, $99 \%$ 의 민감도와 $100 \%$ 의 특이도로 손목굴증 후군을 진단할 수 있다고 하였다. 종단면에서, 원위부에서 근 위부로 정중신경이 손목굴로 주행할 때, 원위부에서 근위부로 의 정중신경영역의 직경변화를 $\mathrm{V}$ 자패임징후이라고 한다. 또 한, 정중신경 내에 칼라 또는 파워도플러 흐름신호가 보이는 경우에도 $95 \%$ 의 정확도로 손목굴증후군을 진단할 수 있다. ${ }^{19}$ 최근에는 신경전도검사가 정상인 손목굴증후군 환자를 진단할 때 초음파가 $92.3 \%$ 의 환자의 손목에서 정중신경팽대 부위를
찾아낼 수 있다고 보고되었다. ${ }^{25}$

정상변이(normal variant)로서, 손목근위부에서 미리 분 지한 정중신경 즉 두갈래정중신경(bifid median nerve)이 있 는데, 보통 두 분지 사이에 잔류정중동맥(persistent median artery)이 관찰되며, 전체 인구의 $2.8 \%$ 에서 관찰된다(Fig. 2). 이러한 경우, 두 개의 정중신경줄기의 합산면적을 네모엎 침근 수준에서 측정하였을 때, 정상보다 $4 \mathrm{~mm}^{2}$ 이상 증가하 면 손목굴증후군으로 진단할 수 있다. ${ }^{26,27}$ 손목굴감압술 후에 도 증상이 지속되는 환자들에서 초음파검사가 도움이 될 수 있 다. 손목굴의 감압 후 정중신경의 초음파 소견이 정상화되기 도 하지만, ${ }^{28}$ 정중신경의 크기가 수술 성공과 연관되지는 않았 다. ${ }^{29}$ 손목굴감압술(carpal tunnel release) 후 굽힘근지지띠는 보통 다시 두꺼워지며, 손바닥쪽으로 탈구되기도 한다. $28,30,31$ 증상이 지속되는 경우에는 초음파로 굽힘근지지띠가 불완전하 게 감압되었거나 혈종이나 신경손상 여부를 파악할 수 있다. 수술하고 수개월 또는 수년 뒤에 증상이 재발되었을 경우에는 손을 많이 쓰는 직업군에서는 흥터조직이 생겼거나 종단면 영 상에서 정중신경의 패임을 확인할 수 있다. ${ }^{32}$

손목굴증후군에서 코르티코스테로이드 국소주사가 장기적 으로 효과가 지속되는지의 여부는 전기진단검사의 중중도에 따라 결정된다. 전기진단검사에서 경도의 이상이 있는 환자 의 절반 이상에서 15 개월 이상 장기적으로 효과가 유지되었다 (Fig. 3). ${ }^{33}$ 최근 $1-\mathrm{mm}$ 초미세 침습 초음파 유도 손목굴감압 술을 2-cm 맹검 소개방 손목굴박리술을 비교한 연구에서 초 미세 침습 손목굴감압술이 소개방 손목굴감압술처럼 동일한 신경회복 효과를 보이면서도 조기에 기능을 회복시키고 술 후 합병증을 감소시켰다. ${ }^{34}$

\section{결 론}

초음파검사는 상지의 압박 및 포착으로 인한 국소신경병의 진단과, 치료를 위한 국소화에 상당히 유용하다. 또한 신경학 적 진찰과 전기진단검사에서 획득할 수 없는 정보를 제공할 수 있기 때문에, 전기진단검사의 보완재로 작용한다. 손목굴증후 군은 초음파의 진단적 가치가 입증된 질환으로, 질환의 중증도 와 병인에 대한 자료를 초음파로 얻을 수 있으며, 초음파유도 주사요법으로 비수술치료도 가능하다. 따라서 포착신경병이 의심될 경우 전기진단검사 중에 또는 검사 후 바로 초음파검사 가 가능하다면 매우 유용할 것이다.

\section{REFERENCES}

1. Zbojniewicz AM. US for diagnosis of musculoskeletal conditions in the young athlete: emphasis on dynamic assess- 
ment. Radiographics. 2014;34:1145-1162.

2. Silvestri E, Martinoli C, Derchi LE, Bertolotto M, Chiaramondia M, Rosenberg I. Echotexture of peripheral nerves: correlation between US and histologic findings and criteria to differentiate tendons. Radiology. 1995;197:291-296.

3. Podnar S. Letter to the editor: can muscle hypertrophy cause entrapment neuropathy? J Neurosurg. 2016;125:16081609 .

4. Jacobson JA, Fessell DP, Lobo Lda G, Yang LJ. Entrapment neuropathies I: upper limb (carpal tunnel excluded). Semin Musculoskelet Radiol. 2010;14:473-486.

5. Omejec G, Žgur T, Podnar S. Diagnostic accuracy of ultrasonographic and nerve conduction studies in ulnar neuropathy at the elbow. Clin Neurophysiol. 2015;126:1797-1804.

6. Podnar S, Sarafov S, Tournev I, Omejec G, Zidar J. Peripheral nerve ultrasonography in patients with transthyretin amyloidosis. Clin Neurophysiol. 2017;128:505-511.

7. Rempel D, Dahlin L, Lundborg G. Pathophysiology of nerve compression syndromes: response of peripheral nerves to loading. J Bone Joint Surg Am. 1999;81:1600-1610.

8. Beekman R, Van Der Plas JP, Uitdehaag BM, Schellens RL, Visser LH. Clinical, electrodiagnostic, and sonographic studies in ulnar neuropathy at the elbow. Muscle Nerve. 2004;30:202-208.

9. Beekman R, Schoemaker MC, Van Der Plas JP, Van Den Berg LH, Franssen H, Wokke JH, et al. Diagnostic value of high-resolution sonography in ulnar neuropathy at the elbow. Neurology. 2004;62:767-773.

10. Klauser AS, Faschingbauer R, Bauer T, Wick MC, Gabl M, Arora R, et al. Entrapment neuropathies II: carpal tunnel syndrome. Semin Musculoskelet Radiol. 2010;14:487-500.

11. Atroshi I, Gummesson C, Johnsson R, Ornstein E, Ranstam J, Rosén I. Prevalence of carpal tunnel syndrome in a general population. JAMA. 1999;282:153-158.

12. Stevens JC, Sun S, Beard CM, O'Fallon WM, Kurland LT. Carpal tunnel syndrome in Rochester, Minnesota, 1961 to 1980. Neurology. 1988;38:134-138.

13. Buchberger W, Schön G, Strasser K, Jungwirth W. High-resolution ultrasonography of the carpal tunnel. J Ultrasound Med. 1991;10:531-537.

14. Keith MW, Masear V, Amadio PC, Andary M, Barth RW, Graham B, et al. Treatment of carpal tunnel syndrome. J Am Acad Orthop Surg. 2009;17:397-405.

15. Peetrons PA, Derbali W. Carpal tunnel syndrome. Semin Musculoskelet Radiol. 2013;17:28-33.

16. Ooi CC, Wong SK, Tan AB, Chin AY, Abu Bakar R, Goh SY, et al. Diagnostic criteria of carpal tunnel syndrome using high-resolution ultrasonography: correlation with nerve conduction studies. Skeletal Radiol. 2014;43:1387-1394.

17. Hunderfund AN, Boon AJ, Mandrekar JN, Sorenson EJ. Sonography in carpal tunnel syndrome. Muscle Nerve. 2011;44:485-491.

18. Ulaşli AM, Duymuş M, Nacir B, Rana Erdem H, Koşar U. Reasons for using swelling ratio in sonographic diagnosis of carpal tunnel syndrome and a reliable method for its calculation. Muscle Nerve. 2013;47:396-402.

19. Mallouhi A, Pülzl P, Trieb T, Piza H, Bodner G. Predictors of carpal tunnel syndrome: accuracy of gray-scale and color Doppler sonography. AJR Am J Roentgenol. 2006;186:12401245 .

20. Naranjo A, Ojeda S, Mendoza D, Francisco F, Quevedo JC, Erausquin C. What is the diagnostic value of ultrasonography compared to physical evaluation in patients with idiopathic carpal tunnel syndrome? Clin Exp Rheumatol. 2007;25:853-859.

21. Wang LY, Leong CP, Huang YC, Hung JW, Cheung SM, Pong YP. Best diagnostic criterion in high-resolution ultrasonography for carpal tunnel syndrome. Chang Gung Med J. 2008;31:469-476.

22. Martinoli C, Bianchi S, Gandolfo N, Valle M, Simonetti $\mathrm{S}$, Derchi LE. US of nerve entrapments in osteofibrous tunnels of the upper and lower limbs. Radiographics. 2000;20:S199-S213; discussion S213-S217.

23. Kuo TT, Lee MR, Liao YY, Chen JP, Hsu YW, Yeh CK. Assessment of median nerve mobility by ultrasound dynamic imaging for diagnosing carpal tunnel syndrome. PLoS One. 2016;11:e0147051.

24. Klauser AS, Halpern EJ, De Zordo T, Feuchtner GM, Arora $\mathrm{R}$, Gruber J, et al. Carpal tunnel syndrome assessment with US: value of additional cross-sectional area measurements of the median nerve in patients versus healthy volunteers. Radiology. 2009;250:171-177.

25. Aseem F, Williams JW, Walker FO, Cartwright MS. Neuromuscular ultrasound in patients with carpal tunnel syndrome and normal nerve conduction studies. Muscle Nerve. 2017;55:913-915.

26. Propeck T, Quinn TJ, Jacobson JA, Paulino AF, Habra G, Darian VB. Sonography and MR imaging of bifid median nerve with anatomic and histologic correlation. AJR Am J Roentgenol. 2000;175:1721-1725.

27. Klauser AS, Halpern EJ, Faschingbauer R, Guerra F, Martinoli C, Gabl MF, et al. Bifid median nerve in carpal tunnel 
syndrome: assessment with US cross-sectional area measurement. Radiology. 2011;259:808-815.

28. Smidt MH, Visser LH. Carpal tunnel syndrome: clinical and sonographic follow-up after surgery. Muscle Nerve. 2008;38:987-991.

29. Abicalaf CA, de Barros N, Sernik RA, Pimentel BF, Braga-Baiak A, Braga L, et al. Ultrasound evaluation of patients with carpal tunnel syndrome before and after endoscopic release of the transverse carpal ligament. Clin Radiol. 2007;62:891-894; discussion 895-896.

30. Lee CH, Kim TK, Yoon ES, Dhong ES. Postoperative morphologic analysis of carpal tunnel syndrome using high-resolution ultrasonography. Ann Plast Surg. 2005;54:143146.

31. Kim JY, Yoon JS, Kim SJ, Won SJ, Jeong JS. Carpal tunnel syndrome: clinical, electrophysiological, and ultrasonographic ratio after surgery. Muscle Nerve. 2012;45:183-188.

32. Tan TC, Yeo CJ, Smith EW. High definition ultrasound as diagnostic adjunct for incomplete carpal tunnel release. Hand Surg. 2011;16:289-294.

33. Visser LH, Ngo Q, Groeneweg SJ, Brekelmans G. Long term effect of local corticosteroid injection for carpal tunnel syndrome: a relation with electrodiagnostic severity. Clin Neurophysiol. 2012;123:838-841.

34. Rojo-Manaute JM, Capa-Grasa A, Chana-Rodríguez F, Perez-Mañanes R, Rodriguez-Maruri G, Sanz-Ruiz P, et al. Ultra-minimally invasive ultrasound-guided carpal tunnel release: a randomized clinical trial. J Ultrasound Med. 2016;35:1149-1157. 